Article

\title{
Impact of Adalimumab Treatment on Interleukin-17 and Interleukin-17 Receptor Expression in Skin and Synovium of Psoriatic Arthritis Patients with Mild Psoriasis
}

\author{
Janne W. Bolt 1,2 ${ }^{\mathbb{D}}$, Arno W. van Kuijk ${ }^{2,3}$, Marcel B. M. Teunissen ${ }^{4} \mathbb{D}$, Dennis van der Coelen ${ }^{1,2}$, \\ Saïda Aarrass ${ }^{1,2}$, Daniëlle M. Gerlag ${ }^{1,2}$, Paul P. Tak ${ }^{1,2,5,6}{ }^{(D}$, Marleen G. van de Sande ${ }^{1,2}$, Maria C. Lebre ${ }^{7, t}$ \\ and Lisa G. M. van Baarsen $1,2, *,+\mathbb{D}$
}

check for updates

Citation: Bolt, J.W.; van Kuijk, A.W.; Teunissen, M.B.M.; van der Coelen, D.; Aarrass, S.; Gerlag, D.M.; Tak, P.P.; van de Sande, M.G.; Lebre, M.C.; van Baarsen, L.G.M. Impact of Adalimumab Treatment on Interleukin-17 and Interleukin-17 Receptor Expression in Skin and Synovium of Psoriatic Arthritis Patients with Mild Psoriasis.

Biomedicines 2022, 10, 324. https: / /doi.org/10.3390/ biomedicines 10020324

Academic Editor: Mario Dell'Agli

Received: 20 December 2021

Accepted: 24 January 2022

Published: 29 January 2022

Publisher's Note: MDPI stays neutral with regard to jurisdictional claims in published maps and institutional affiliations.

Copyright: (c) 2022 by the authors Licensee MDPI, Basel, Switzerland. This article is an open access article distributed under the terms and conditions of the Creative Commons Attribution (CC BY) license (https:// creativecommons.org/licenses/by/ $4.0 /)$.
1 Department of Rheumatology and Clinical Immunology, Amsterdam Rheumatology \& Immunology Center (ARC), Amsterdam UMC, University of Amsterdam, 1105 AZ Amsterdam, The Netherlands; j.w.bolt@amsterdamumc.nl (J.W.B.); kir@amsterdamumc.nl (D.v.d.C.); kir@amc.uva.nl (S.A.); dmgerlag@gmail.com (D.M.G.); tak.paulpeter@gmail.com (P.P.T.); m.g.vandesande@amsterdamumc.nl (M.G.v.d.S.)

2 Department of Rheumatology, Amsterdam Rheumatology \& Immunology Center (ARC)-Reade, 1040 HG Amsterdam, The Netherlands; a.v.kuijk@reade.nl

3 Department of Rheumatology, Reade, 1056 AB Amsterdam, The Netherlands

4 Department of Dermatology, Amsterdam UMC, University of Amsterdam, 1105 AZ Amsterdam, The Netherlands; m.b.teunissen@amsterdamumc.nl

5 Candel Therapeutics, Needham, MA 02494, USA

6 Internal Medicine, Cambridge University, Cambridge CB2 1TN, UK

7 The Netherlands Cancer Institute, Division of Pharmacology, Plesmanlaan 121, 1066 CX Amsterdam, The Netherlands; c.lebre@nki.nl

* Correspondence: e.g.vanbaarsen@amsterdamumc.nl

+ These authors contributed equally to this work.

Abstract: Interleukin (IL)-17 and tumor necrosis factor-alpha (TNF)- $\alpha$ are key players in psoriatic arthritis (PsA) pathogenesis. While both cytokines can be therapeutically targeted with beneficial clinical outcome, it is unclear whether inhibiting one cytokine will affect the other at sites of inflammation. If both act independently, this might provide a rationale for dual or combined inhibition of both cytokines. Here, we evaluated the effect of TNF blockade in PsA patients on IL-17 levels in both skin and synovial tissue biopsies. PsA patients with mild psoriatic skin lesions were randomized to receive either adalimumab or placebo for four weeks. Synovial and skin biopsies were obtained at weeks zero and four. Skin from healthy donors (HDs) was used for comparison. Expression of IL-17A, IL-17F, IL-17RA and IL-17RC was assessed by immunohistochemistry and analyzed with digital image analysis. We found relatively low levels of IL-17 and its receptors in the skin of PsA patients compared to HD, and only IL-17F in the dermis of lesional psoriatic skin was significantly higher compared to HD skin ( $p=0.0002)$. Histologically IL-17A, IL-17F, IL-17RA and IL-17RC in skin and synovial tissue were not downregulated by adalimumab treatment. Thus, in this cohort of PsA patients with mild psoriasis, TNF blockade did not affect the protein levels of IL-17 cytokines and its receptors in skin and synovium, despite reduced cellular inflammation and improved clinical outcome for joint involvement.

Keywords: psoriatic arthritis; skin; synovium; interleukin-17; adalimumab; immunopathogenesis; immunohistochemistry

\section{Introduction}

Psoriatic arthritis (PsA) is a chronic inflammatory joint disorder characterized by musculoskeletal manifestations such as arthritis, spondylitis, dactylitis spinal involvement and enthesitis, and extra articular features such as psoriatic skin lesions [1]. The use of conventional synthetic disease modifying antirheumatic drugs (csDMARDs), and especially 
biological (b) DMARDs, has drastically improved treatment outcomes in PsA. Despite this, disease remission is still not achieved in all PsA patients, and the efficacy of the various treatments differs from one person to the next, and can decrease over time [2]. The pathogenesis of PsA is not yet fully elucidated, but it is clear that the immune pathways active in PsA can vary according to the site of tissue inflammation. Tumor necrosis factoralpha (TNF- $\alpha$ ) and interleukin (IL)-17 are key cytokines in the pathogenesis of PsA [1]. IL-17A is the most widely studied and most biological active cytokine of the IL-17 family (IL17 A-F), and is produced by, e.g., CD4+ T cells, CD8+ T cells, gamma delta T cells, natural killer T cells (NKT), mast cells, and innate lymphoid cells [3-5]. Gene expression and protein levels of IL-17A, C and F are increased in affected skin lesions, nonlesional skin and synovial tissue of PsA patients $[3,6]$, which result in the release of other pro-inflammatory cytokines and chemokines, the promotion of angiogenesis, and bone remodeling [7]. IL-17A works in synergy with IL-17F; these cytokines are similar, although the latter is less potent than the former [4]. Little is known about the function of IL-17C and the other IL-17 family members (IL-17D and IL-17E) in PsA [8].

TNF- $\alpha$ is upregulated in the blood, skin and synovium of PsA patients $[9,10]$, and is mainly produced by macrophages. By binding to TNF receptors, TNF- $\alpha$ activates kinases, phosphor-proteins and nuclear factor kappa $B$, which leads to pro-inflammatory gene transcription, cytokine secretion, cytotoxic effects and differentiation of T-helper cells [11]. In psoriatic skin, TNF- $\alpha$ can activate myeloid dendritic cells (DCs) that produce IL-23, resulting in the activation of IL-17A secreting T cells and innate lymphoid cells $[12,13]$. Additionally, it was shown in synovium of rheumatoid arthritis patients that TNF- $\alpha$ stimulates attraction of DCs and IL-17A secreting T cells [14]. The importance of the TNF- $\alpha$ and IL-23/IL-17A axis in disease pathogenesis is well described for psoriasis [15] and psoriatic arthritis [16].

TNF- $\alpha$ also synergizes with IL-17 to stimulate inflammation in general, and studies in rheumatoid arthritis patients, in both ex vivo and gene expression experiments, showed that this results in increased levels of inflammatory mediators, higher levels of granulopoiesis and exacerbation of bone destruction by higher production of RANKL $[17,18]$.

Both TNF inhibitors and IL-17A inhibitors are effective in the treatment of PsA [19-23]. Therapeutic application of bDMARDS, including TNF inhibitors, IL-17A inhibitors, or IL-12/IL-23 inhibitors, is advised after failure of csDMARDs treatment [24-26]. Compared to TNF inhibitors, IL-17A inhibitors have shown superior therapeutic efficacy on psoriatic skin lesions in PsA, and may therefore be primarily considered in patients with significant skin involvement $[17,27,28]$. As there is still no ideal treatment for PsA, i.e., one that induces remission in all patients, it is important to determine whether IL-17 expression is affected by the inhibition of TNF- $\alpha$, and vice versa, or whether both bDMARDS downregulate inflammation by independent mechanisms. TNF blockers, such as adalimumab, might also affect the synergistic effects between IL-17 and TNF, and as a consequence, diminish the inflammatory process without directly affecting IL-17. Currently, information is lacking on whether TNF blockade is partly effective due to indirect modulation of the levels of IL-17A, IL-17F and their receptors in (nonlesional and lesional) the skin and synovium of PsA patients.

The purpose of this exploratory study was to investigate the impact of TNF blockade on IL-17 levels in target tissues by evaluating the effects of adalimumab treatment on IL-17A, IL-17F and their receptors in paired skin and synovial tissue biopsies of patients suffering from PsA with moderate psoriasis lesions.

\section{Materials and Methods}

\subsection{Study Design}

As described in the original study [29,30], we performed a randomized, doubleblind, placebo-controlled, single-center study at the Amsterdam UMC of the University of Amsterdam (Current Controlled Trials ISRCTN23328456). The local Medical Ethics Committee approved the study, and patients gave their written informed consent before 
they participated in the study. We collected information from the medical history of the study patients, and patients underwent physical examination by both a rheumatologist and a dermatologist. After randomization, patients received either adalimumab $(n=12)$ or placebo $(n=12)$ at baseline (day 1$)$ and day 15 as previously described [29,30]. Twentyfour PsA patients that fulfilled the ClASsification of Psoriatic ARthritis (CASPAR) criteria aged 18-80 years were included in the study [31,32]. Patients were eligible if they had at least two tender and two swollen joints out of the 68 joints assessed for tenderness and 66 joints assessed for swelling. One of the swollen joints had to be accessible for arthroscopy. Concomitant treatment with nonsteroidal anti-inflammatory drugs (NSAIDs) and/or methotrexate was allowed if the dosage was stable for a minimum of 28 days. Other DMARDs were not allowed 1 month prior baseline, and a washout period of 2 months was necessary for leflunomide use. Parenteral, intra-articular or oral use of corticosteroids within 28 days before enrolment into the study was not allowed. Topical treatments for psoriasis were not allowed 14 days prior to baseline, except for low potency (class I) topical steroids to be used on scalp, palms, groin and/or soles of feet only [29,30]. Demographics and clinical features at baseline from the original study can be found in Table 1 [29].

Table 1. Demographic and clinical characteristics at baseline of the 24 patients with psoriatic arthritis.

\begin{tabular}{|c|c|c|c|c|}
\hline & \multicolumn{2}{|c|}{ Adalimumab $(n=12)$} & \multicolumn{2}{|c|}{ Placebo $(n=12)$} \\
\hline Sex, female/male $(n)$ & $9 / 3$ & & $6 / 6$ & \\
\hline Age, years & 42.8 & $(21-61)$ & 47.2 & $(25-78)$ \\
\hline Patients on MTX, number (\%) & 7 & $(58 \%)$ & 5 & $(42)$ \\
\hline MTX dose, mg/week & 18.2 & $(10-25)$ & 19 & $(15-25)$ \\
\hline Duration of psoriasis, years & 8.8 & $(0.1-27.7)$ & 20.8 & $(1.9-53.2)$ \\
\hline Duration of PsA, years & 5.5 & $(0.4-14.1)$ & 8.4 & $(1.9-18.2)$ \\
\hline DAS28 score & 4.67 & $(3.0-5.78)$ & 5.07 & $(2.21-6.83)$ \\
\hline VAS disease activity $(0-100 \mathrm{~mm})$ & 73 & $(45-94)$ & 62.8 & $(18-92)$ \\
\hline VAS pain $(0-100 \mathrm{~mm})$ & 72.8 & $(55-91)$ & 67.4 & $(11-89)$ \\
\hline $\mathrm{CRP}, \mathrm{mg} /$ liter & 19.9 & $(2.3-81.6)$ & 9.9 & $(1.3-26.7)$ \\
\hline $\mathrm{ESR} \mathrm{mm} / \mathrm{h}$ & 24.2 & $(4-66)$ & 22.4 & $(3-66)$ \\
\hline PASI & 5.89 & $(0-14.0)$ & 4.72 & $(0-7.0)$ \\
\hline
\end{tabular}

All values are mean (range) except where indicated otherwise. MTX, methotrexate; PsA, psoriatic arthritis, DAS, disease activity score; VAS, visual analogue scale $(100 \mathrm{~mm})$; CRP, C-reactive protein; ESR, erythrocyte sedimentation rate, PASI, psoriasis area severity index.

The mean psoriasis area severity index (PASI) did not significantly change in the placebo group and the adalimumab group [30]. The mean disease activity score (DAS) 28 decreased significantly from 4.67 (SD 0.98) to 2.87 (1.27) in the adalimumab group, while the DAS28 remained approximately stable in the placebo group [29].

\subsection{Skin and Synovial Tissue Biopsies}

At baseline and week 4, patients had to undergo 4-mm punch biopsies from the lesional and nonlesional skin, preferentially from areas that were not exposed to sun. The second biopsy was preferably taken from the same psoriatic plaque that was targeted at baseline, separated by at least $1 \mathrm{~cm}$ [30]. We collected skin samples from 22 PsA patients. Available tissue data from baseline lesional and nonlesional PsA skin samples were compared with normal adult skin $(n=15)$ obtained from healthy donors (HD)s undergoing plastic surgery of the breast or abdomen. A mini-arthroscopy of an actively inflamed joint (knee, ankle, or wrist) was performed under local anesthesia in all patients before treatment and 28 days (same joint) after initiation of study medication [29].

Paired skin samples from 18 patients and paired synovial samples from 19 PsA patients were available for analysis $[29,30]$.

The tissue samples were randomly coded and after this snap-frozen in Tissue-Tek OCT compound (Sakura Finetek Europe, Zoeterwoude, The Netherlands) by immersion in 
liquid nitrogen. Before immunohistochemical stainings, five-micrometer cryostat sections were cut and mounted on glass slides and stored at $-80^{\circ} \mathrm{C}$.

\subsection{Skin and Synovial Biopsy Immunohistochemical Staining}

Skin and synovial tissue were stained with mouse monoclonal antibodies against IL-17A (IgG1, clone 41802), IL-17F (IgG2a, clone 197315) and their receptors IL-17 receptor(R)A (IgG1, clone 133617) and IL-17RC (IgG2b, clone 309882), all from R\&D Systems (Minneapolis, MN, USA). Briefly, after tissue fixation with acetone, endogenous peroxidase activity was inhibited using $0.1 \%$ sodium azide and $0.3 \%$ hydrogen peroxide in phosphate buffered saline (PBS). The primary mouse monoclonal antibodies against human IL-17A, IL-17F and their receptors IL-17RA and IL-17RC were incubated overnight at $4{ }^{\circ} \mathrm{C}$ followed by secondary antibody affinity-purified horseradish peroxidase (HRP)-conjugated goat antimouse (Dako Cytomation, Glostrup, Denmark) for $30 \mathrm{~min}$. After this step incubation with biotinylated tyramide (Perkin Elmer, Boston, MA, USA) was performed for $30 \mathrm{~min}$ and HRP-conjugated streptavidin was performed for $30 \mathrm{~min}$ (to detect IL-17A, IL-17F and IL-17RA) or followed by BrightVision (Immunologic, Duiven, The Netherlands; to detect IL-17RC). Detection of HRP-activity was performed with of hydrogen peroxide as substrate and amino ethylcarbazole (AEC; SK-4200; Vector Laboratories, Burlingame, CA, USA) as dye resulting in positive cells staining in red. Mayer's hematoxilin (Merck, Darmstadt, Germany) was used for counterstaining and, after washing with distilled water, mounted in Kayser's glycerol gelatine (Merck). As negative control, irrelevant isotype-matched immunoglobulins were applied to the sections instead of the primary antibody.

\subsection{Quantification of IL-17A-, IL-17F-, IL17RA- and IL-17RC-Expressing Cells in Skin and Synovium}

Quantification of IL-17A-, IL-17F-, IL17RA- and IL-17RC-expressing cells in PsA skin and synovial tissues was performed by computer-assisted image analysis, as previously described [29]. Briefly, after immunohistochemical staining, all coded sections (one section per patient per time-point) were randomly analyzed (18 high-power fields from different parts of the section were analyzed; the mean of the 18 high-power fields was calculated). The images of the high-power fields were analyzed using the Qwin analysis system (Leica, Cambridge, UK). The expression of stained proteins was calculated for each section as the median integrated optical density (IOD) $/ \mathrm{mm}^{2}$ [33].

\subsection{Statistical Analysis}

The expression of IL-17A, IL-17F, IL17RA and IL-17RC in HD skin and PsA at baseline were compared using GraphPad Prism Software (V.5, GraphPad Software, La Jolla, CA, USA) and evaluation of statistical differences were performed with Kruskall-Wallis test with post-Dunn's multiple comparison tests or nonparametric Mann Whitney U-test where appropriate. We considered $p$ values below 0.05 as statistically significant. SPSS version 15.0 for Windows (SPSS, Chicago, IL, USA) was used to evaluate statistical differences between the effects of each treatment group (placebo vs. adalimumab). An analysis of covariance model (ANCOVA) after rank transformation was used to correct for baseline differences [34].

\section{Results}

3.1. Expression of IL-17A, IL-17F and Their Receptors in Skin of Psoriatic Arthritis Patients Compared to Healthy Donors

IL-17 levels were analyzed in the skin of 15 HDs and compared with lesional and nonlesional skin samples from 22 PsA patients.

In the lesional PsA skin, we observed typical psoriasis features, such as parakeratotic hyperkeratosis, acanthosis, perivascular lymphocyte infiltration and elongated rete ridges (Figures 1A, 2A, 3A, 4A and 5). 
A
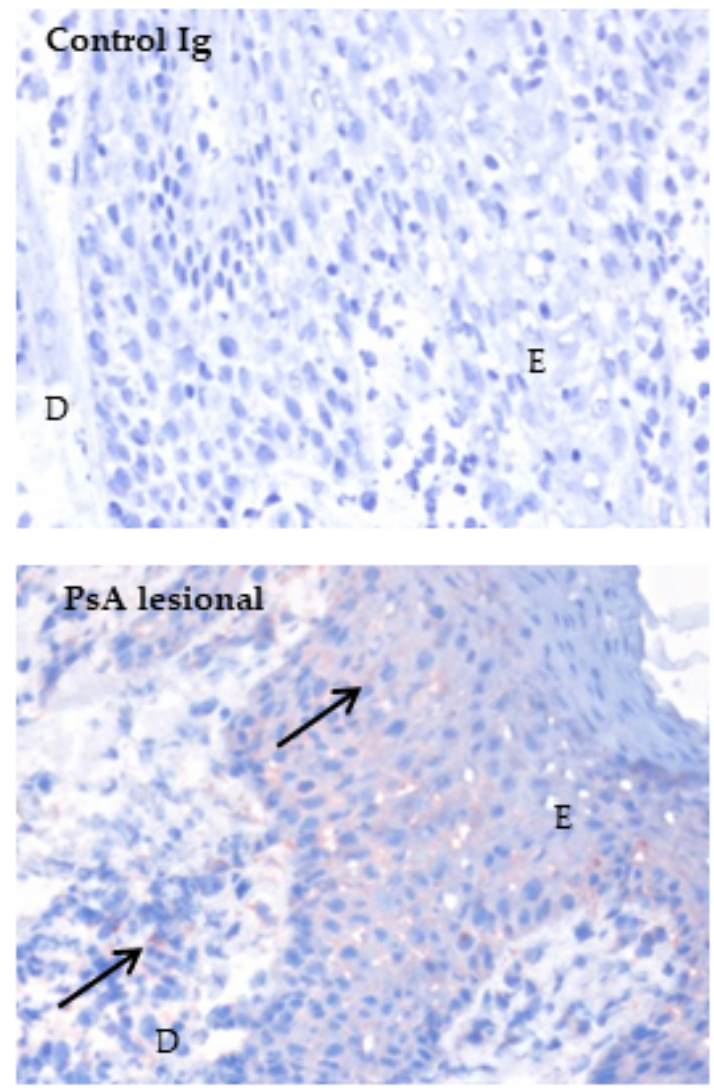
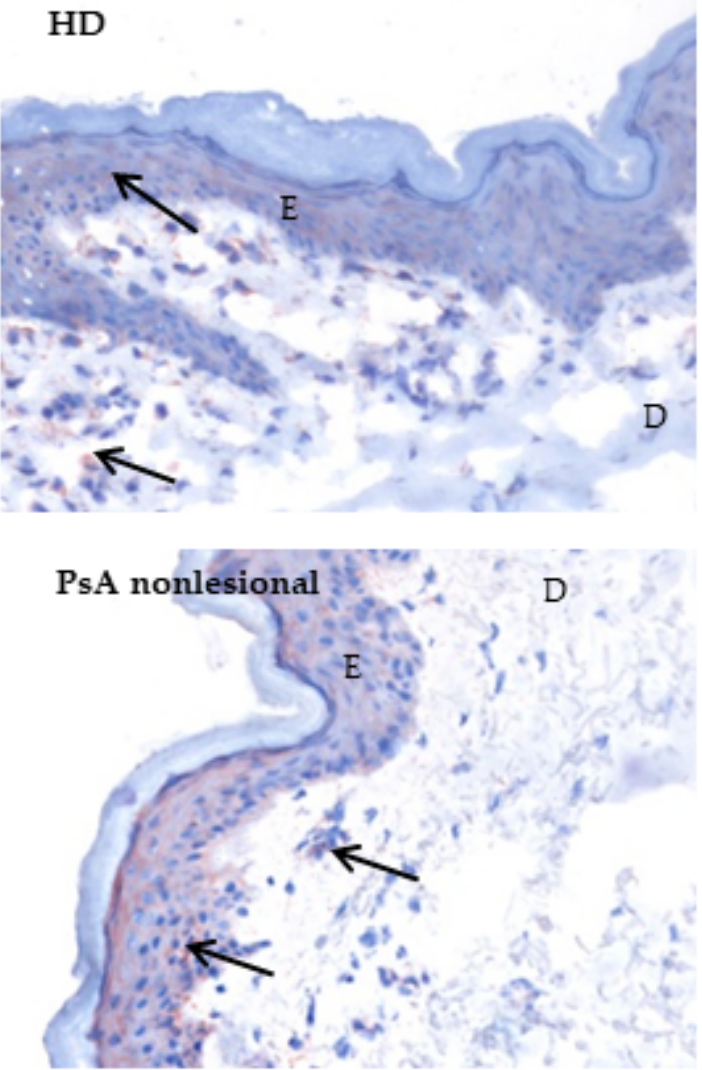

B

IL-17A epidermis

IL-17A dermis
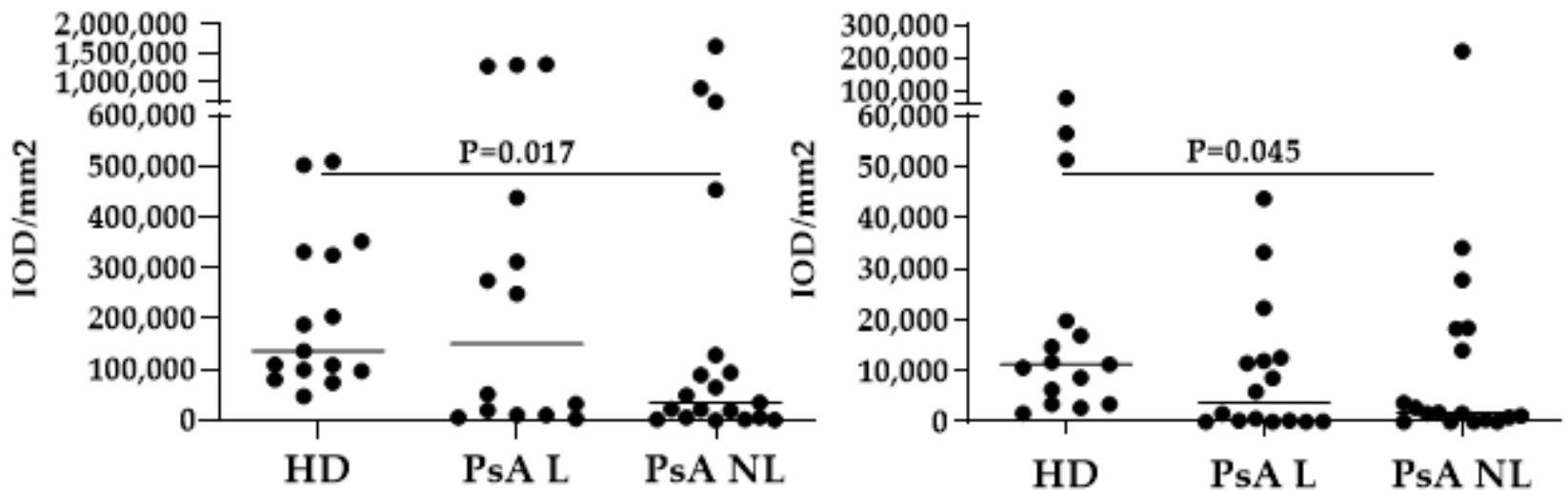

Figure 1. Expression of IL-17A was lower in the epidermis and dermis of nonlesional psoriatic skin compared to healthy donor skin. (A) Representative immunohistochemical staining of baseline IL-17A expression (arrows) in skin from HD and PsA patients. Original magnification $200 \times$. (B) Quantification of IL-17A (Kruskal-Wallis test, epidermis $p=0.07$, dermis $p=0.07$ ) and expression in HD, PsA L skin and PsA NL skin. Results are shown as median IOD $/ \mathrm{mm}^{2}$ and IQR of epidermis and dermis of HD and PsA patients. Per subject the median expression level of 18 high-power fields is used for analysis. E, epi-dermis; D, dermis; IL, interleukin; HD, healthy donor; PsA, psoriatic arthritis; L; lesional, NL; nonlesional, IOD; integrated optical density, IQR; interquartile range. 
A
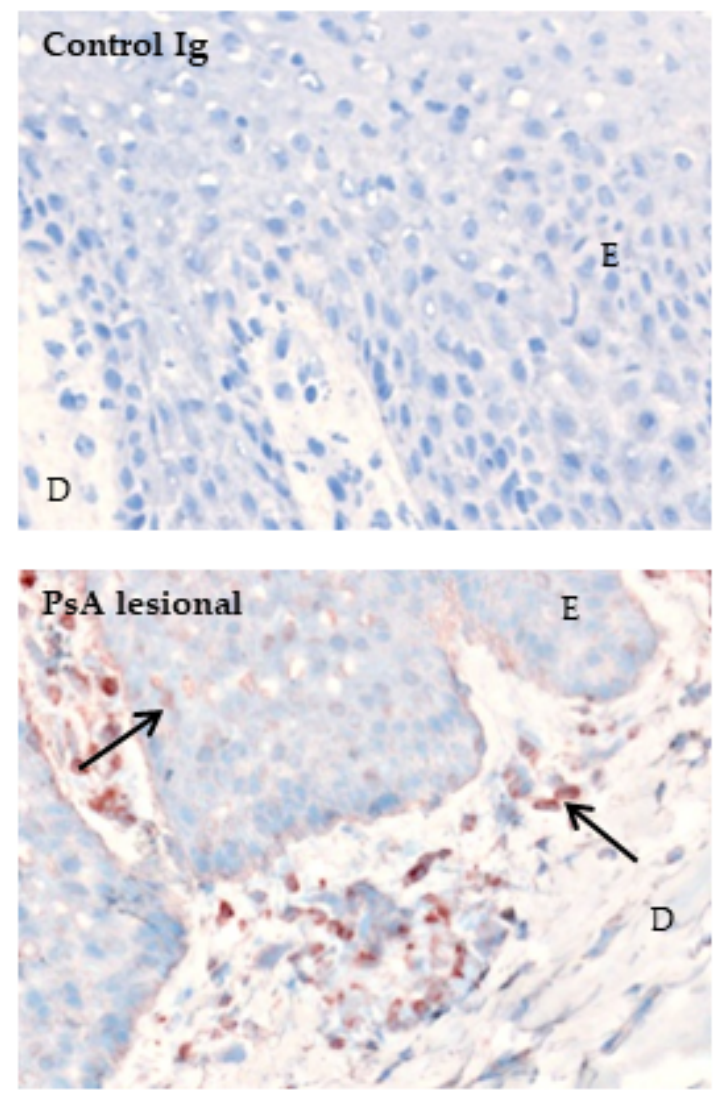
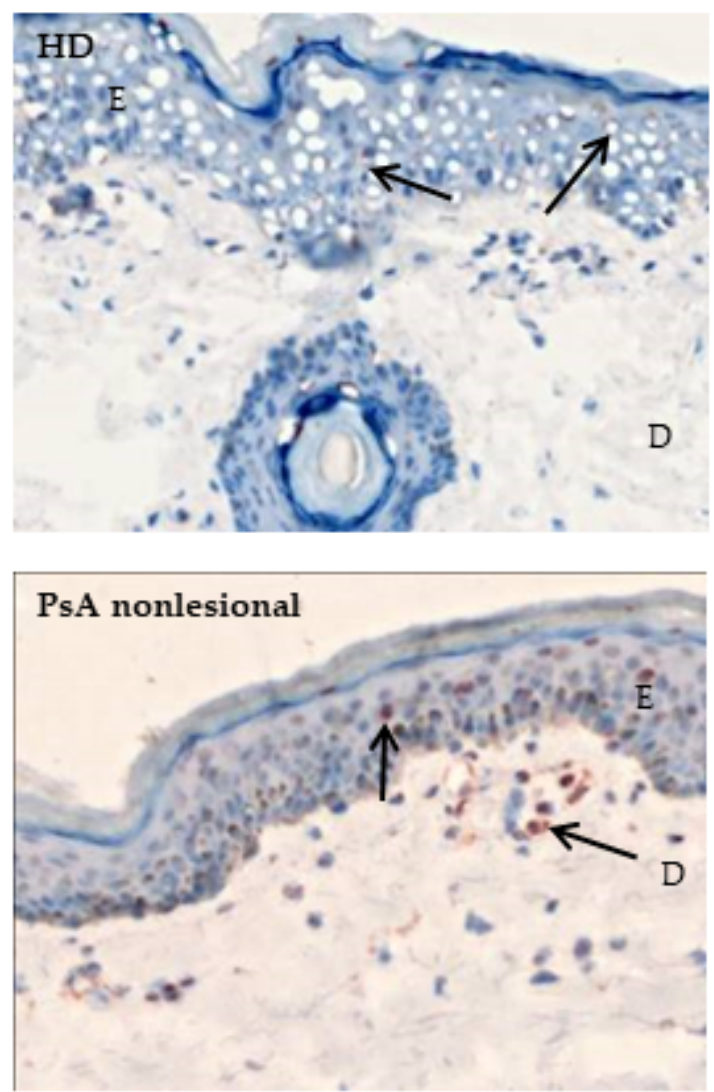

B

\section{IL-17F epidermis}

IL-17F dermis

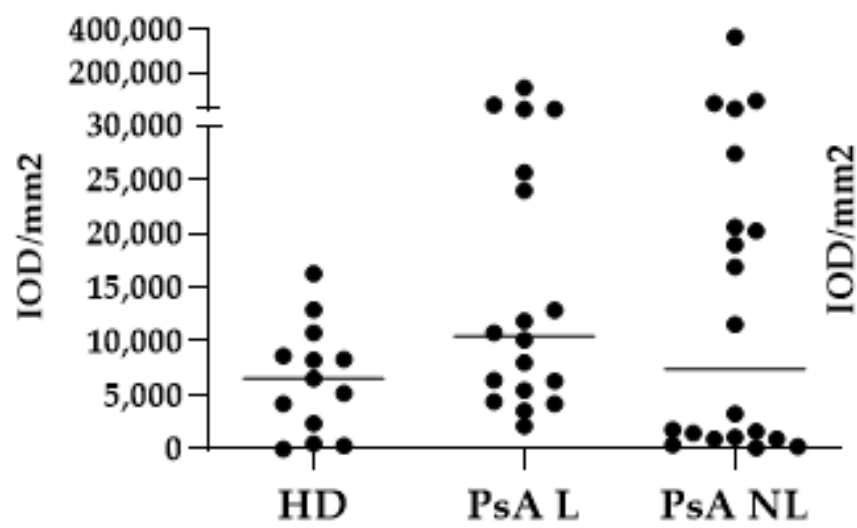

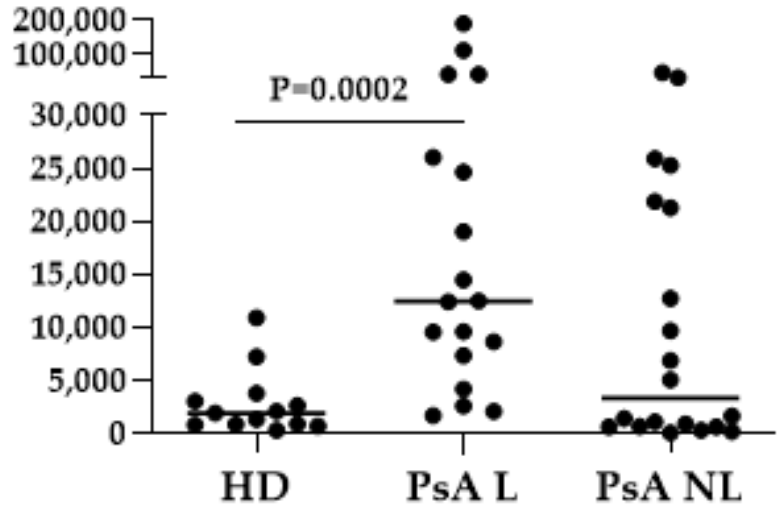

Figure 2. Expression of IL-17F was higher in the dermis of lesional psoriatic skin compared to healthy donor skin. (A) Representative immunohistochemical staining of baseline IL-17F expression (arrows) in skin from HD and PsA patients. Original magnification $200 \times$. (B) Quantification of IL-17F (Kruskal-Wallis test, epidermis $p=0.17$, dermis $p=0.0002$ ) expression in HD, PsA L skin and PsA NL skin. Results are shown as median IOD $/ \mathrm{mm}^{2}$ and IQR of epidermis and dermis of HD and PsA patients. Per subject the median expression level of 18 high-power fields is used for analysis. $p$ values given in the graphs are cal-culated from a post Dunn's test. E, epidermis; D, dermis; IL, interleukin; HD, healthy donor; PsA, psoriatic arthritis; L; lesional, NL; nonlesional, IOD; integrated optical density, IQR; interquartile range. 
A
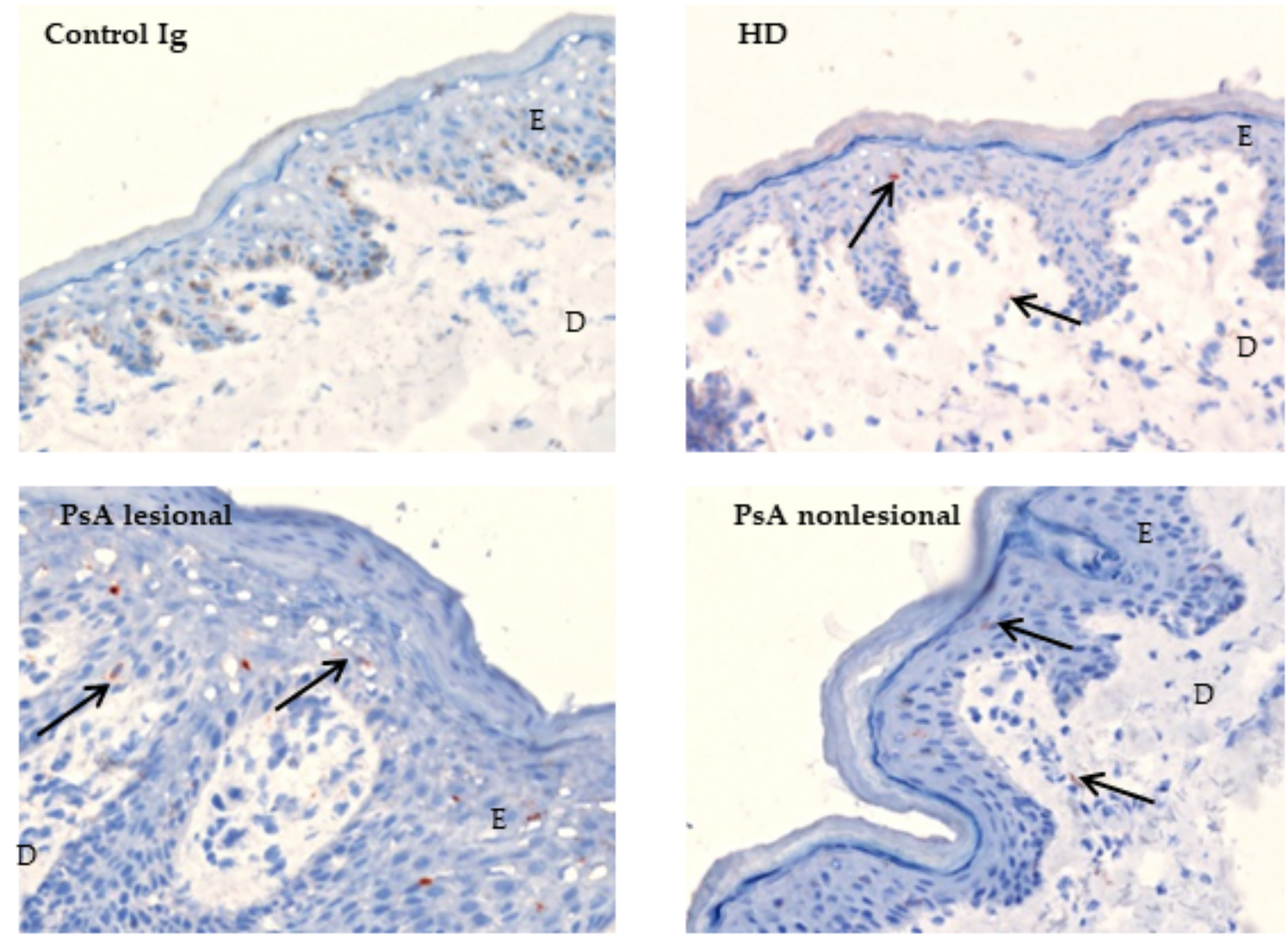

B

\section{IL-17RA epidermis}

\section{IL-17RA dermis}
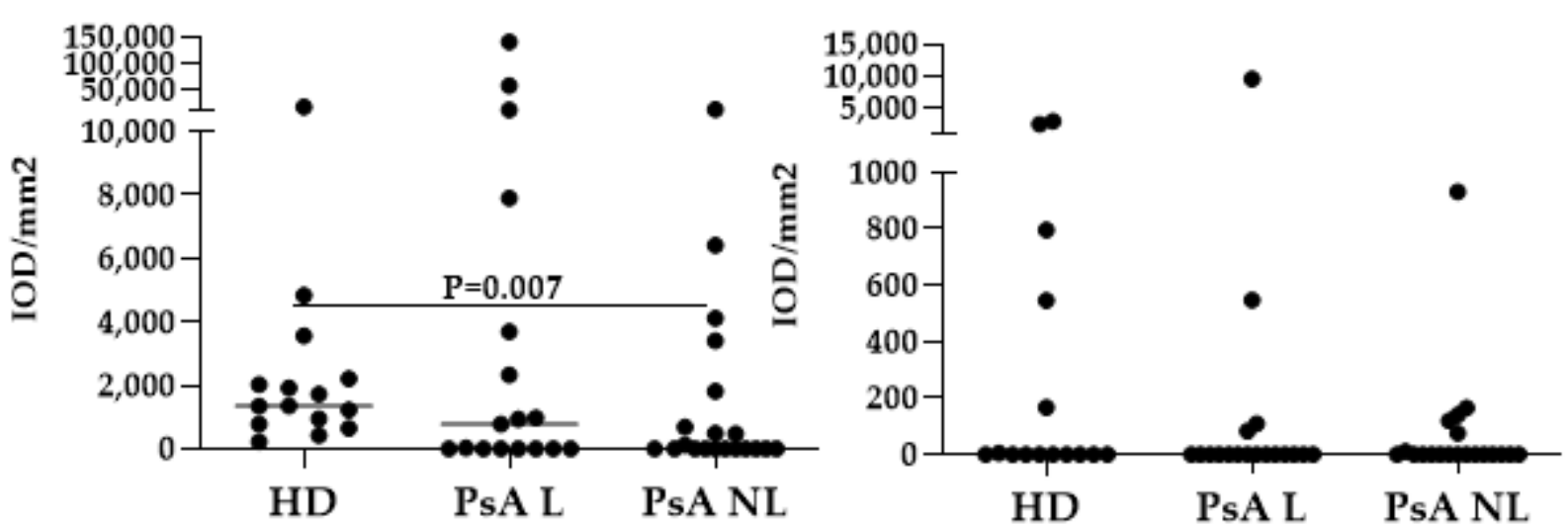

Figure 3. Expression of IL-17RA was lower in the epidermis of the nonlesional psoriatic skin compared to healthy donor skin. (A) Representative immunohistochemical staining of baseline IL-17RA expression (arrows) in skin from HD and PsA patients. Original magnification $200 \times$. (B) Quantification of IL-17RA (Kruskal-Wallis test, epidermis $p=0.03$, dermis $p=0.007$ ) expression in HD, PsA L skin and PsA NL skin. Results are shown as median IOD $/ \mathrm{mm}^{2}$ and IQR of epidermis and dermis of HD and PsA patients. Per subject the median expression level of 18 high-power fields is used for analysis. $p$ values given in the graphs are calculated from a post Dunn's test. E, epidermis; D, dermis, IL, interleukin; HD, healthy donor; PsA, psoriatic arthritis; L; lesional, NL; nonlesional, IOD; integrated optical density, IQR; interquartile range. 
A
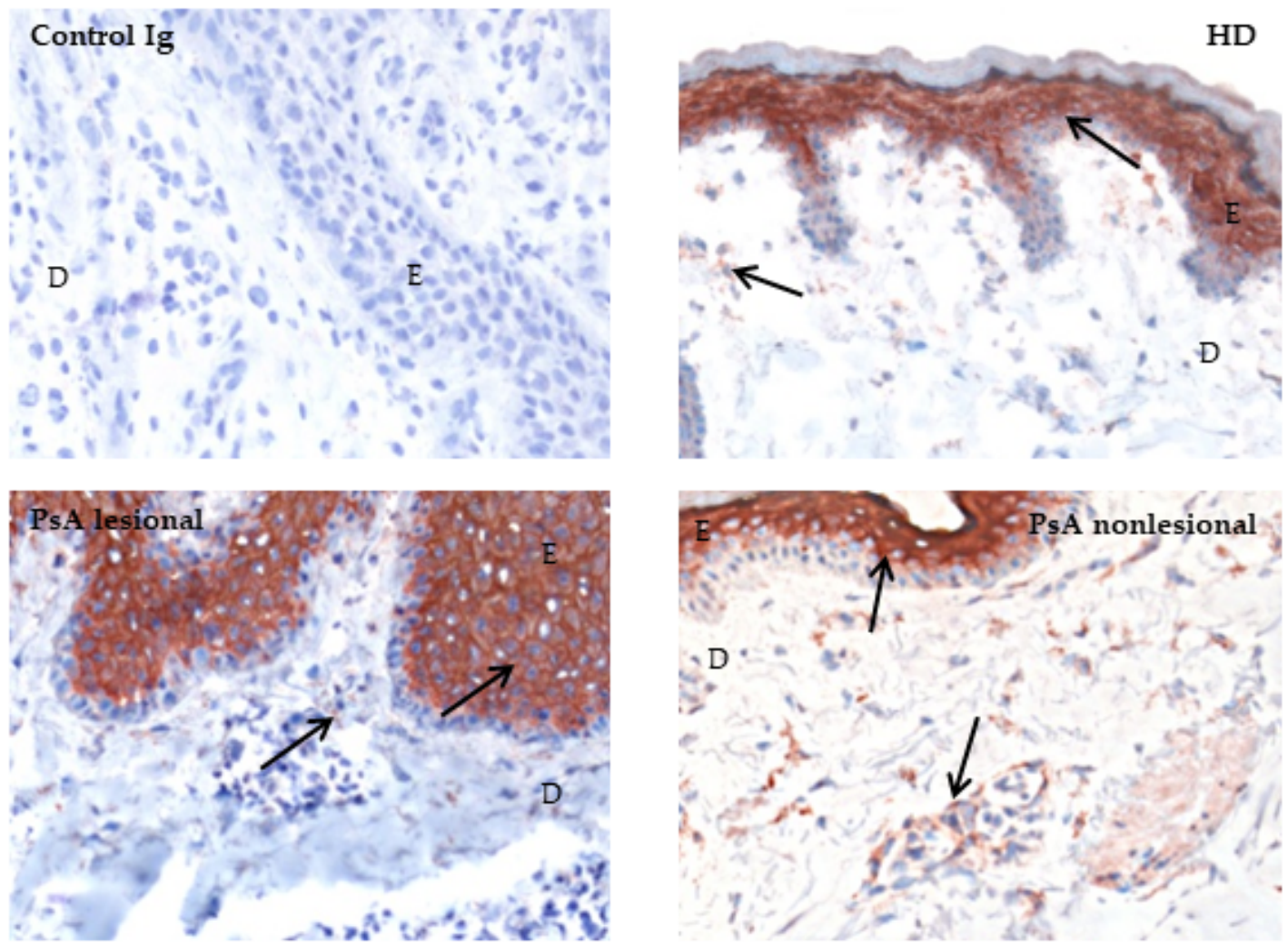

B

\section{IL-17RC epidermis}

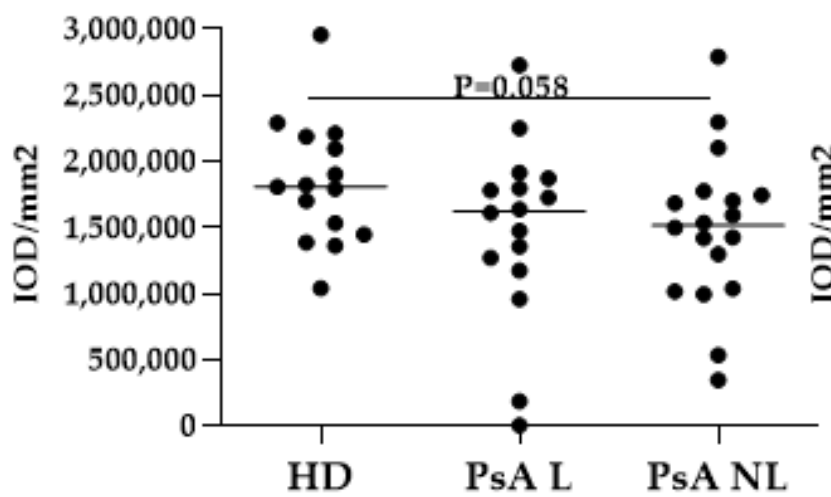

\section{IL-17RC dermis}

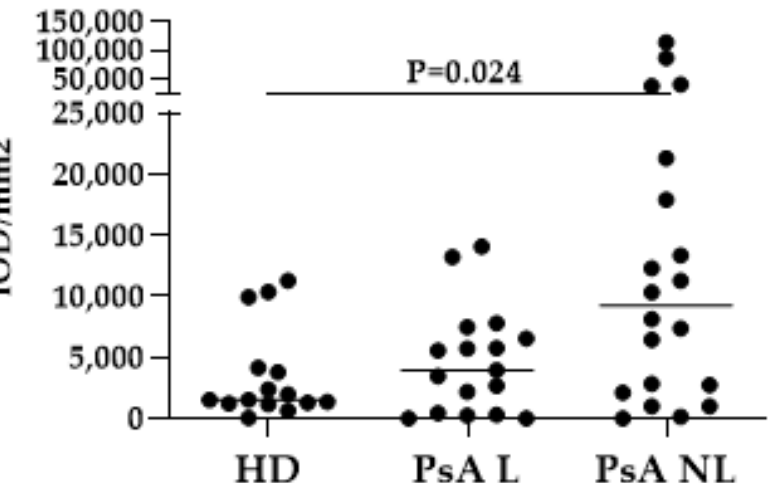

Figure 4. Expression of IL-17RC in psoriatic skin was higher in the dermis of nonlesional psoriatic skin compared to healthy donor skin. (A) Representative immunohistochemical staining of baseline IL-17RC expression (arrows) in skin from HD and PsA patients. Original magnification $200 \times$. (B) Quantification of IL-17RC (Kruskal-Wallis test, epidermis $p=0.13$, dermis $p=0.03$ ) expression in HD, PsA L skin and PsA NL skin. Results are shown as median IOD $/ \mathrm{mm}^{2}$ and IQR of epidermis and dermis of HD and PsA patients. Per subject the median expression level of 18 high-power fields is used for analysis. $p$ values given in the graphs are calculated from a post Dunn's test. E, epidermis; D, dermis, IL, interleukin; HD, healthy donor; PsA, psoriatic arthritis; L; lesional, NL; nonlesional, IOD; integrated optical density, IQR; interquartile range. 
A
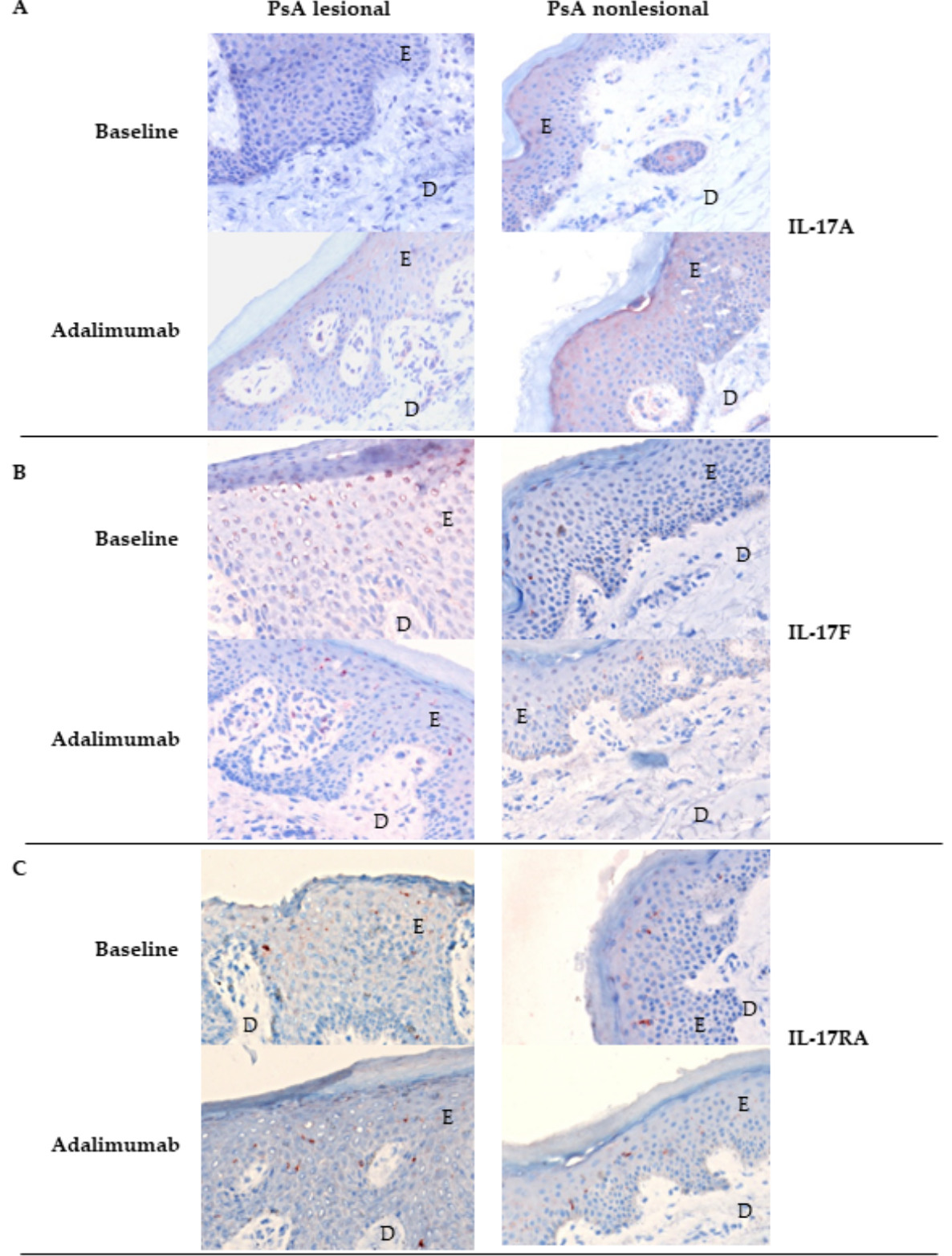

D

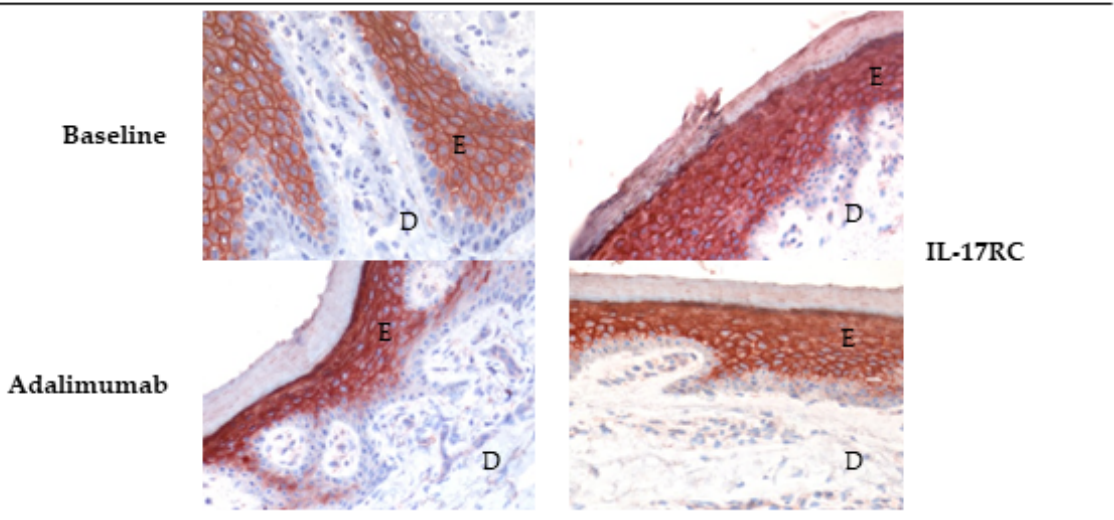

Figure 5. Representation of expression of IL-17A, IL-17F, IL-17RA and IL-17RC in psoriatic skin of one PsA patient before and after adalimumab treatment. Expression was not altered after 4 weeks of adalimumab. Representative immunohistochemical staining of IL-17A (A), IL-17F (B), IL-17RA (C) and IL-17RC (D) expression in skin of one PsA patient before (baseline) and after treatment with adalimumab. Original magnification $200 \times$. E; epidermis, D; dermis, IL, interleukin; PsA, psoriatic arthritis. 
IL-17A expression showed a highly variable, diffuse and cytoplasmatic pattern (Figure 1A, arrows) in the epidermis, as well as in the dermis. Surprisingly, the levels of IL-17A were significantly lower in the epidermis and dermis of nonlesional PsA skin compared to HD skin (Figure $1 \mathrm{~B}, p=0.017$ and $p=0.045$, respectively). No significant differences were observed in the expression of IL-17A between lesional and nonlesional PsA skin (both in the epidermis and dermis).

The expression of IL-17F showed a more cellular staining pattern (Figure 2A). In contrast to IL-17A, IL-17F was more expressed in the dermis of PsA lesional skin compared to HD skin (Figure 2B, $p=0.0002$ ). No other significant differences were observed in the expression of IL-17F between lesional and nonlesional PsA skin (both in the epidermis and dermis), but levels were highly variable between patients.

IL-17RA was frequently expressed to varying degrees, mainly through the epidermis and, to a lesser extent, in the dermis (Figure 3A). The expression of IL-17RA was significantly reduced in the epidermis of lesional PsA skin compared to HD skin (Figure 3B, $p=0.007$ ), while no differences were observed in the dermis.

IL-17RC was abundantly expressed in the epidermis, but it was also found in dispersed cells throughout the dermis (Figure 4A). The expression of IL-17RC was significantly higher in the dermis of nonlesional PsA skin compared to HD skin (Figure 4B, right graph, $p=0.024$ ), while IL-17RC expression levels were not significantly different in the epidermis.

\subsection{Expression of IL-17A,IL-17F and Their Receptors in Skin of Psoriatic Arthritis Patients Treated with Placebo Compared to Adalimumab}

Available paired pre- and post- treatment skin and synovium tissue samples were used to quantify differences in the expression levels of each marker for each patient (in $\mathrm{IOD} / \mathrm{mm}^{2}$ ) before and after treatment [29,30]. For each endpoint, ANCOVA was applied to correct for baseline differences between the placebo- and adalimumab-treated groups, and to compare the effect of adalimumab versus placebo after four weeks of treatment on IL-17 levels in skin and synovium. After 4 weeks of treatment, there was only a significant difference between the change in IL-17RA expression in the lesional dermis of the adalimumab group compared the lesional dermis of the placebo group (ANCOVA $p=0.01$ ). This was not found for the other nonlesional and lesional IL-17RA expression levels in the epidermis and dermis. Of interest was the observation that the median expression of IL17RA in the epidermis of the adalimumab group at baseline was $0 \mathrm{IOD} / \mathrm{mm}^{2}$. There were no significant differences after ANCOVA was applied for IL-17A (Table 2), IL-17F and IL17RC alteration levels between placebo- and adalimumab-treated groups in the epidermis and dermis $(p>0.05)$. Overall, no clear effect was observed in IL-17 expression in skin upon adalimumab treatment. This is shown in Figure 5, which illustrates immunohistochemistry staining in skin tissues of one PsA patient before and after therapy with adalimumab. 
Table 2. Median IOD $/ \mathrm{mm}^{2}$ values of IL-17 expression in lesional and nonlesional skin before and after treatment with adalimumab compared to placebo.

\begin{tabular}{|c|c|c|c|c|c|c|c|c|}
\hline & \multirow[b]{2}{*}{ Skin Tissue } & \multicolumn{3}{|c|}{ Adalimumab $(n=10)$} & \multicolumn{3}{|c|}{ Placebo $(n=11)$} & \multirow{2}{*}{$\begin{array}{c}\text { ANCOVA } \\
p \text { Value }\end{array}$} \\
\hline & & $\begin{array}{l}\text { IOD/mm }{ }^{2} \\
\text { Baseline }\end{array}$ & & $\begin{array}{c}\mathrm{IOD} / \mathrm{mm}^{2} \\
\text { Change upon Treatment }\end{array}$ & $\begin{array}{l}\mathrm{IOD} / \mathrm{mm}^{2} \\
\text { Baseline }\end{array}$ & & $\begin{array}{c}\mathrm{IOD} / \mathrm{mm}^{2} \\
\text { Change upon Treatment }\end{array}$ & \\
\hline \multirow{2}{*}{ IL-17A } & epidermis & 130,024 & $(1421-406,897)$ & 1621 & 32,938 & $(10,501-75,100)$ & 2351 & 0.818 \\
\hline & dermis & 7261 & $(62-12,426)$ & 43 & 687 & $(110-11,503)$ & 440 & 0.990 \\
\hline \multirow{2}{*}{ IL-17F } & epidermis & 8127 & $(4276-20,978)$ & 1583 & 10,155 & $(6351-30,021)$ & -6139 & 0.945 \\
\hline & dermis & 13,436 & $(2979-25,674)$ & 9257 & 9591 & $(7997-29,477)$ & 1379 & 0.812 \\
\hline \multirow{2}{*}{ IL-17RA } & epidermis & 942 & $(0-3695)$ & 893 & 37 & $(0-4439)$ & 0 & 0.010 \\
\hline & dermis & 0 & $(0-42)$ & 447 & 0 & $(0-0)$ & 1 & 0.215 \\
\hline IL-17RC & dermis & 5762 & $(389-7648)$ & -3496 & 2679 & $(247-5577)$ & 1270 & 0.332 \\
\hline \multirow{2}{*}{ IL-17A } & epidermis & 21,892 & $(1015-20,420)$ & 323 & 35,249 & $(5714-91,372)$ & 3513 & 0.945 \\
\hline & dermis & 3297 & $(385-11,211)$ & 189 & 1719 & $(461-7907)$ & 2436 & 0.083 \\
\hline \multirow{2}{*}{ IL-17F } & epidermis & 1646 & $(0-1255)$ & 415 & 10,093 & $(365-39,274)$ & 2372 & 0.760 \\
\hline & dermis & 893 & $(0-44)$ & 969 & 5960 & $(970-22,719)$ & 644 & 0.914 \\
\hline \multirow{2}{*}{ IL-17RA } & epidermis & 129 & $(773,173-1,689,893)$ & 0 & 0 & $(0-1399)$ & 321 & 0.194 \\
\hline & dermis & 0 & $(2378-25,450)$ & 0 & 0 & $(0-30)$ & 0 & 0.454 \\
\hline \multirow{2}{*}{ IL-17RC } & epidermis & $1,496,622$ & $(1421-406,897)$ & 48,011 & $1,508,035$ & $(1,100,136-2,156,572)$ & 213,162 & 0.339 \\
\hline & dermis & 10,226 & $(62-12,426)$ & -3942 & 7371 & $(1554-14,607)$ & -1483 & 0.375 \\
\hline
\end{tabular}

IL-17A, IL-17F, IL-17RA and IL-17RC IOD $/ \mathrm{mm}^{2}$ are expressed as median (IQR). Change upon treatment is expressed as median. A positive or negative value for change represents an increase or decrease in IOD, respectively. ANCOVA was applied to correct for baseline imbalance between placebo and adalimumab treatment groups. IOD; Integrated optical density, $\mathrm{IQR}$; interquartile range. 
IL-17A and IL-17F expression were found both in the intimal lining layer and sublining of the synovium, and IL-17RA and IL-17RC were ubiquitously expressed (Figure 6).

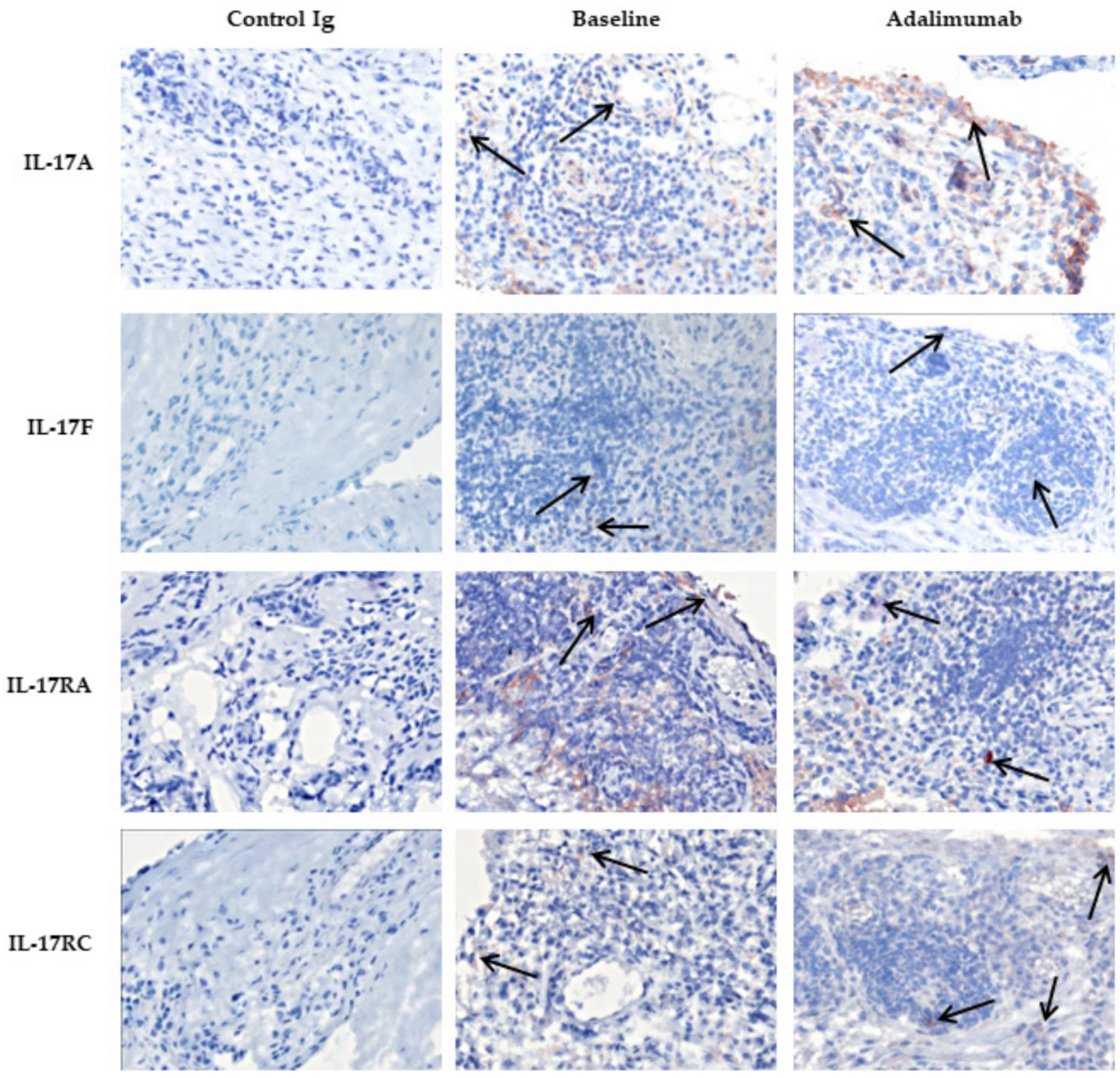

Figure 6. Representation of expression of IL-17A, IL-17F, IL-17RA and IL-17RC (arrows) in synovial tissue of one PsA patient before and after adalimumab treatment. Expression was not altered after 4 weeks of adalimumab. Representative immunohistochemical staining of IL-17A, IL-17F, IL-17RA and IL-17RC expression in synovial tissue of one PsA patient before (baseline) and after treatment with adalimumab. Original magnification $200 \times$. IL, interleukin; PsA, psoriatic arthritis.

Adalimumab treatment did not affect the expression of IL-17A, IL-17F, IL17RA or IL-17RC in PsA synovial tissue compared to the tissue of the placebo group, as all ANCOVA $p$-values were above 0.05 (Table 3). This was also illustrated by the immunohistochemistry of one PsA patient treated with adalimumab; see Figure 6.

Overall, we found no significant positive correlation between IL-17 tissue levels and clinically relevant measurements such as C-reactive protein (CRP), erythrocyte sedimentation rate (ESR), PASI and DAS28 score. 
Table 3. Median IOD $/ \mathrm{mm}^{2}$ values of IL-17 expression in synovial tissue before and after treatment with adalimumab compared to placebo.

\begin{tabular}{|c|c|c|c|c|c|c|c|}
\hline \multirow[b]{2}{*}{ Synovial Tissue } & \multicolumn{3}{|c|}{ Adalimumab $(n=11)$} & \multicolumn{3}{|c|}{ Placebo $(n=10)$} & \multirow[b]{2}{*}{$\begin{array}{l}\text { ANCOVA } \\
p \text { Value }\end{array}$} \\
\hline & $\begin{array}{l}\text { IOD/mm² } \\
\text { Baseline }\end{array}$ & & $\begin{array}{l}\mathrm{IOD} / \mathrm{mm}^{2} \\
\text { Change upon } \\
\text { Treatment }\end{array}$ & & $\begin{array}{l}\mathrm{IOD} / \mathrm{mm}^{2} \\
\text { Baseline }\end{array}$ & $\begin{array}{l}\mathrm{IOD} / \mathrm{mm}^{2} \\
\text { Change upon } \\
\text { Treatment }\end{array}$ & \\
\hline IL-17A & 7322 & $(1464-11,314)$ & 12,211 & 2082 & $(228-17,070)$ & 1581 & 0.333 \\
\hline IL-17F & 19,297 & $(795-43,043)$ & 4509 & 9146 & $(1015-21,304)$ & 5495 & 0.811 \\
\hline IL-17RA & 18,562 & $(2596-107,978)$ & -3676 & 682 & $(470-37,101)$ & 2337 & 0.451 \\
\hline IL-17RC & 3330 & $(1337-14,102)$ & 283 & 3934 & $(800-5249)$ & 230 & 0.385 \\
\hline
\end{tabular}

IL-17A, IL-17F, IL-17RA and IL-17RC IOD/ $\mathrm{mm}^{2}$ are expressed as median (IQR). Change upon treatment is expressed as median. A positive or negative value for change represents an increase or decrease in IOD, respectively. ANCOVA was applied to correct for baseline imbalance between placebo and adalimumab treatment groups. IOD; Integrated optical density, IQR; interquartile range. 


\section{Discussion}

This is the first study to address the protein levels of IL-17A, IL-17F and their receptors in the skin of PsA patients with mild psoriasis (mean PASI score $<10$ ) in comparison with HD skin. Additionally, it evaluated the early effects of adalimumab treatment on the expression of these molecules in both nonlesional and lesional skin and paired inflamed synovium samples of PsA patients.

Overall, the histological expression levels of IL-17A, IL-17F, IL-17RA and IL-17RC in skin were highly variable among the PsA patients in our cohort. IL-17F levels were increased in the lesional dermis of PsA patients compared to HD skin, while IL-17A levels were not increased. This is in line with previous reports that found a higher IL-17F to IL-17A ratio on gene expression level in psoriatic skin [6]. In our cohort, the overall levels of IL-17A and IL-17F appeared low, as other studies have observed relatively high expression levels of these genes in psoriatic lesional skin compared to nonlesional psoriatic skin $[6,35]$. We found a lower level of IL-17RA in lesional psoriatic skin compared to HD skin and a higher expression of IL-17RC in the dermal nonlesional PsA skin compared to HD, which is not in line with earlier findings of increased gene expression levels of IL-17RA [35]. Possibly, the lower levels of IL-17A and IL-17RC observed in our study can be explained by the mild skin phenotype in our patients, as the median PASI in our study was 5.80, and only two patients had a PASI score just above 10, while other psoriatic skin studies reported PASI scores higher than 10 [35-37]. In addition, gene expression levels of total skin tissue biopsies may not correlate with protein levels quantified for either epidermis or dermis, especially for secreted cytokines, which are overall more challenging to quantify using immunohistochemistry [38]. Furthermore, we measured the IL-17 levels in IOD $/ \mathrm{mm}^{2}$, which reflects IL-17 levels per square millimeter tissue but does not reflect the total presence of IL-17 protein levels in skin lesions, which often contain thickening of the epidermal layer, and thus, potentially harbor higher total IOD scores.

Several mechanisms for indirect downregulation of IL-17 levels by TNF blockade have been proposed. It was found in the skin lesions of psoriasis patients that TNF blockade with etanercept prevented TNF-mediated activation of myeloid dendritic cells, resulting in decreased IL-23 driven T-cell activation and a subsequent decrease in IL-17 levels in the skin [13]. Another study of psoriasis patients showed that the downregulation of IL-17 was caused by a decrease of IL-17R gene expression in keratinocytes after etanercept treatment [39]. In this study, we were unable to confirm the downregulation of either IL-17A or IL-17F. This may be explained by possible differences in molecular responses to the various TNF blockers, or by the relatively low IL-17 tissue levels observed at baseline in our study, which makes it more difficult to detect changes.

After four weeks of adalimumab treatment, we showed that there was no decrease in protein levels of IL-17A and IL-17F or their receptors in synovium and skin in our cohort of PsA patients with mild psoriasis. This was also not found in the skin and synovium samples from patients with significant improvements in the PASI or DAS28. In another study with psoriasis patients, IL-17 gene expression levels in the skin were decreased after 14 days of treatment with etanercept [39], but this study reported a much higher median body surface area (BSA) score for psoriasis, and thus, consisted of patients with more severe psoriasis. As the IL-17 protein levels detected in the skin of our PsA cohort were not very high, it may have been more difficult to observe a clear downregulation upon treatment. Although we observed a significant increase for IL-17RA in the epidermis of lesional skin of PsA patients after adalimumab treatment, the increase was relatively low, and significance was lost after adjustment for multiple comparisons.

Though placebo-controlled, this study only included a limited number of patients, which makes it possible that we have missed small effects on cytokine expression.

Initially, this study was designed to investigate the early effects of adalimumab on inflammation in synovium and skin. As the inclusion criteria were based on disease activity, swollen and tender joint counts, rather than the current extent of skin involvement, we 
included patients with low PASI scores and accordingly found smaller changes in PASI score upon adalimumab treatment compared to other cutaneous psoriasis trials [40].

Although there was no significant clinical improvement in the skin, a significant decrease in cellular infiltrate and DAS28 improvement was observed after four weeks of adalimumab [29,30]. All together this implies that in this cohort the clinical and cellular improvement after four weeks of treatment with adalimumab was probably independent of IL-17A, IL17-F, IL-17RA and IL-17RC levels.

Due to sample collection only after four weeks of adalimumab treatment, it is not excluded that IL-17 cytokine and receptor modulation is delayed and only effective after a longer period of treatment. This is stressed by the fact that the clinical efficacy of TNF- $\alpha$ blockade treatment with adalimumab starts already after 2 weeks, but is optimal after 12 weeks in terms of joint scores and 16 weeks in terms of skin scores [41]. Our study results are in line with two studies that observed no decrease in IL-17 blood levels in spondyloarthritis patients treated with TNF-inhibitors for 2 years [42] and 6 months [43]. The studies that evaluated IL-17 levels in blood samples have to be interpreted with caution as it is questionable whether these levels align with the effects on IL-17 levels observed target tissue like synovium and psoriatic skin.

Of interest, another study found also no alterations in TNF mRNA levels in synovial tissues of PsA patients who were treated for 12 weeks with secukinumab, a monoclonal anti-IL17A antibody [44]. These and our findings suggest that the reduced synovial and skin inflammation observed in PsA patients after blocking of IL-17A is independent of changes in TNF levels, and vice versa, blocking of TNF is independent of changes in IL-17A levels.

Our findings are of significance as the overall absence in downregulation of synovial and skin IL-17 protein levels upon TNF blockade supports the rationale that treatment of PsA patients with a combination of TNF and IL-17 blockers might be more beneficial, although the current study cannot exclude that changes in IL-17 levels might occur after a longer treatment duration. So far bispecific biologicals did not show an additional clinical effect compared to monotherapy with TNF blockade [45]. To the best of our knowledge, this is the first study documenting the effects of TNF-blockade on protein levels of IL-17 cytokines and receptors in paired skin and synovium samples of PsA patients.

\section{Conclusions}

Altogether, our study shows that after four weeks of adalimumab treatment in PsA patients with mild skin involvement, TNF-blockade did not downregulate IL-17 cytokine and receptor protein levels in synovium and skin, despite improvement of the cellular infiltrate in both skin and synovium as well as clinical improvement, as measured by DAS28 score $[29,30]$.

Author Contributions: All authors meet the criteria for authorship and more specifically for contributorship statement: J.W.B., M.G.v.d.S., M.C.L., M.B.M.T. and L.G.M.v.B. analyzed and interpreted the data and wrote the article under the close supervision of P.P.T. and thereby take responsibility for this work. M.B.M.T., A.W.v.K., D.M.G. and P.P.T. conceived the study, participated in its design and coordination. D.M.G. and A.W.v.K. collected and supplied the clinical data. D.v.d.C., M.B.M.T. and S.A. acquired the experimental data; J.W.B., M.C.L. and L.G.M.v.B. performed statistical analysis. All authors agreed to publish this work and critically reviewed the article. Conception and design of this work were discussed with all authors. All authors have read and agreed to the published version of the manuscript.

Funding: This research was funded the Innovative Medicines Initiatives (IMI) European Union (EU) funded project BeTheCure (nr115142) and ZonMw VIDI grant (nr91718371). The clinical part of the study was funded by Abbott BV, The Netherlands. Abbot BV had no role in the study design or in the collection, analysis, or interpretation of the data, the writing of this manuscript, or the decision to submit the manuscript for publication. Publication of this article was not contingent upon approval by Abbot BV. 
Institutional Review Board Statement: The study was conducted according to the guidelines of the Declaration of Helsinki, and approved by the Institutional Review Board (or Ethics Committee) of the Academic Medical Center of the University of Amsterdam (Current Controlled Trials ISRCTN23328456).

Informed Consent Statement: Informed consent was obtained from all subjects involved in the study.

Data Availability Statement: The data presented in this study are available on request from the corresponding author. The data are currently not publicly available.

Acknowledgments: The authors would like to thank all participating patients, A.H. Zwinderman (Department of Clinical Epidemiology and Biostatistics, Academic Medical Center/University of Amsterdam, Amsterdam, The Netherlands) and M. de Hair for advice with statistical analysis. We thank the van Leeuwenhoek Centre for Advanced Microscopy (LCAM) at the AMC for microscopy.

Conflicts of Interest: The authors declare no conflict of interest. The authors declare that they have no competing interests. DMG is currently working at UCBpharma and PPT is currently working at Candel Therapeutics, both companies had no role in this project.

\section{References}

1. Ritchlin, C.; Colbert, R.A.; Gladman, D.D. Psoriatic Arthritis. N. Engl. J. Med. 2017, 376, 957-970. [CrossRef] [PubMed]

2. Kavanaugh, A.; Helliwell, P.; Ritchlin, C.T. Psoriatic Arthritis and Burden of Disease: Patient Perspectives from the PopulationBased Multinational Assessment of Psoriasis and Psoriatic Arthritis (MAPP) Survey. Rheumatol. Ther. 2016, 3, 91-102. [CrossRef]

3. Xu, X.; Davelaar, N.; Mus, A.; Asmawidjaja, P.S.; Hazes, J.M.W.; Baeten, D.L.P.; Vis, M.; Bisoendial, R.J.; Prens, E.P.; Lubberts, E. Interleukin-17A Is Produced by CD4+ but Not CD8+ T Cells in Synovial Fluid Following T Cell Receptor Activation and Regulates Different Inflammatory Mediators Compared to Tumor Necrosis Factor in a Model of Psoriatic Arthritis Synovitis. Arthritis Rheumatol. 2020, 72, 1303-1313. [CrossRef] [PubMed]

4. Taams, L.S.; Steel, K.J.A.; Srenathan, U.; Burns, L.A.; Kirkham, B.W. IL-17 in the immunopathogenesis of spondyloarthritis. Nat. Rev. Rheumatol. 2018, 14, 453-466. [CrossRef] [PubMed]

5. Blauvelt, A.; Chiricozzi, A. The Immunologic Role of IL-17 in Psoriasis and Psoriatic Arthritis Pathogenesis. Clin. Rev. Allergy Immunol. 2018, 55, 379-390. [CrossRef]

6. $\quad$ Chen, J.S.; Blijdorp, I.C.; Van Mens, L.J.; Bowcutt, R.; Latuhihin, T.E.; Van De Sande, M.G.; Shaw, S.; Yeremenko, N.G.; Baeten, D.L. Interleukin 17A and IL-17F Expression and Functional Responses in Rheumatoid Arthritis and Peripheral Spondyloarthritis. J. Rheumatol. 2020, 47, 1606-1613. [CrossRef] [PubMed]

7. Chiricozzi, A.; Suarez-Farinas, M.; Fuentes-Duculan, J.; Cueto, I.; Li, K.; Tian, S.; Brodmerkel, C.; Krueger, J. Increased expression of interleukin-17 pathway genes in nonlesional skin of moderate-to-severe psoriasis vulgaris. Br. J. Dermatol. 2015, 174, 136-145. [CrossRef]

8. Yeremenko, N. Out of the shadow of interleukin-17A: The role of interleukin-17F and other interleukin-17 family cytokines in spondyloarthritis. Curr. Opin. Rheumatol. 2021, 33, 333-340. [CrossRef] [PubMed]

9. Van Kuijk, A.W.R.; Reinders-Blankert, P.; Smeets, T.J.M.; Dijkmans, B.A.C.; Tak, P.P. Detailed analysis of the cell infiltrate and the expression of mediators of synovial inflammation and joint destruction in the synovium of patients with psoriatic arthritis: Implications for treatment. Ann. Rheum. Dis. 2006, 65, 1551-1557. [CrossRef] [PubMed]

10. Fiocco, U.; Sfriso, P.; Oliviero, F.; Roux-Lombard, P.; Scagliori, E.; Cozzi, L.; Lunardi, F.; Calabrese, F.; Vezzù, M.; Dainese, S.; et al. Synovial effusion and synovial fluid biomarkers in psoriatic arthritis to assess intraarticular tumor necrosis factor- $\alpha$ blockade in the knee joint. Arthritis Res. Ther. 2010, 12, R148. [CrossRef] [PubMed]

11. Pfeffer, K. Biological functions of tumor necrosis factor cytokines and their receptors. Cytokine Growth Factor Rev. 2003, 14, 185-191. [CrossRef]

12. Singh, T.P.; Zhang, H.H.; Borek, I.; Wolf, P.; Hedrick, M.N.; Singh, S.P.; Kelsall, B.L.; Clausen, B.; Farber, J.M. Monocyte-derived inflammatory Langerhans cells and dermal dendritic cells mediate psoriasis-like inflammation. Nat. Commun. 2016, 7, 13581. [CrossRef]

13. Zaba, L.C.; Cardinale, I.; Gilleaudeau, P.; Sullivan-Whalen, M.; Suárez-Fariñas, M.; Fuentes-Duculan, J.; Novitskaya, I.; Khatcherian, A.; Bluth, M.J.; Lowes, M.A.; et al. Amelioration of epidermal hyperplasia by TNF inhibition is associated with reduced Th17 responses. J. Exp. Med. 2007, 204, 3183-3194. [CrossRef]

14. Chabaud, M.; Page, G.; Miossec, P. Enhancing Effect of IL-1, IL-17, and TNF- $\alpha$ on Macrophage Inflammatory Protein-3 $\alpha$ Production in Rheumatoid Arthritis: Regulation by Soluble Receptors and Th2 Cytokines. J. Immunol. 2001, 167, 6015-6020. [CrossRef] [PubMed]

15. Lowes, M.A.; Russell, C.; Martin, D.A.; Towne, J.E.; Krueger, J.G. The IL-23/T17 pathogenic axis in psoriasis is amplified by keratinocyte responses. Trends Immunol. 2013, 34, 174-181. [CrossRef] [PubMed]

16. Silvagni, E.; Missiroli, S.; Perrone, M.; Patergnani, S.; Boncompagni, C.; Bortoluzzi, A.; Govoni, M.; Giorgi, C.; Alivernini, S.; Pinton, P.; et al. From Bed to Bench and Back: TNF- $\alpha$, IL-23/IL-17A, and JAK-Dependent Inflammation in the Pathogenesis of Psoriatic Synovitis. Front. Pharmacol. 2021, 12, 672515. [CrossRef] 
17. Zrioual, S.; Ecochard, R.; Tournadre, A.; Lenief, V.; Cazalis, M.-A.; Miossec, P. Genome-Wide Comparison between IL-17A- and IL-17F-Induced Effects in Human Rheumatoid Arthritis Synoviocytes. J. Immunol. 2009, 182, 3112-3120. [CrossRef] [PubMed]

18. Osta, B.; Lavocat, F.; Eljaafari, A.; Miossec, P. Effects of Interleukin-17A on Osteogenic Differentiation of Isolated Human Mesenchymal Stem Cells. Front. Immunol. 2014, 5, 425. [CrossRef] [PubMed]

19. Gladman, D.D.; Mease, P.J.; Ritchlin, C.; Choy, E.H.S.; Sharp, J.T.; Ory, P.A.; Perdok, R.J.; Sasso, E.H. Adalimumab for longterm treatment of psoriatic arthritis: Forty-eight week data from the adalimumab effectiveness in psoriatic arthritis trial. Arthritis Care Res. 2007, 56, 476-488. [CrossRef] [PubMed]

20. Nash, P.; Kirkham, B.; Okada, M.; Rahman, P.; Combe, B.; Burmester, G.-R.; Adams, D.H.; Kerr, L.; Lee, C.; Shuler, C.L.; et al. Ixekizumab for the treatment of patients with active psoriatic arthritis and an inadequate response to tumour necrosis factor inhibitors: Results from the 24-week randomised, double-blind, placebo-controlled period of the SPIRIT-P2 phase 3 trial. Lancet 2017, 389, 2317-2327. [CrossRef]

21. McInnes, I.B.; Mease, P.J.; Kirkham, B.; Kavanaugh, A.; Ritchlin, C.; Rahman, P.; van der Heijde, D.; Landewé, R.; Conaghan, P.; Gottlieb, A.B.; et al. Secukinumab, a human anti-interleukin-17A monoclonal antibody, in patients with psoriatic arthritis (FUTURE 2): A randomised, double-blind, placebo-controlled, phase 3 trial. Lancet 2015, 386, 1137-1146. [CrossRef]

22. Mease, P.J.; Kivitz, A.J.; Burch, F.X.; Siegel, E.L.; Cohen, S.B.; Ory, P.; Salonen, D.; Rubenstein, J.; Sharp, J.T.; Tsuji, W. Etanercept treatment of psoriatic arthritis: Safety, efficacy, and effect on disease progression. Arthritis Care Res. 2004, 50, 2264-2272. [CrossRef] [PubMed]

23. Kavanaugh, A.; Van Der Heijde, D.; McInnes, I.B.; Mease, P.; Krueger, G.G.; Gladman, D.D.; Gómez-Reino, J.; Papp, K.; Baratelle, A.; Xu, W.; et al. Golimumab in psoriatic arthritis: One-year clinical efficacy, radiographic, and safety results from a phase III, randomized, placebo-controlled trial. Arthritis Care Res. 2012, 64, 2504-2517. [CrossRef] [PubMed]

24. Coates, L.C.; Kavanaugh, A.; Mease, P.J.; Soriano, E.R.; Acosta-Felquer, M.L.; Armstrong, A.W.; Bautista-Molano, W.; Boehncke, W.-H.; Campbell, W.; Cauli, A.; et al. Group for Research and Assessment of Psoriasis and Psoriatic Arthritis 2015 Treatment Recommendations for Psoriatic Arthritis. Arthritis Rheumatol. 2016, 68, 1060-1071. [CrossRef]

25. Gossec, L.; Baraliakos, X.; Kerschbaumer, A.; de Wit, M.; McInnes, I.; Dougados, M.; Primdahl, J.; McGonagle, D.G.; Aletaha, D.; Balanescu, A.; et al. EULAR recommendations for the management of psoriatic arthritis with pharmacological therapies: 2019 update. Ann. Rheum. Dis. 2020, 79, 700-712. [CrossRef] [PubMed]

26. Singh, J.A.; Guyatt, G.; Ogdie, A.; Gladman, D.D.; Deal, C.; Deodhar, A.; Dubreuil, M.; Dunham, J.; Husni, M.E.; Kenny, S.; et al. 2018 American College of Rheumatology/National Psoriasis Foundation Guideline for the Treatment of Psoriatic Arthritis. Arthritis Care Res. 2019, 71, 2-29. [CrossRef] [PubMed]

27. McInnes, I.B.; Behrens, F.; Mease, P.J.; Kavanaugh, A.; Ritchlin, C.; Nash, P.; Masmitja, J.G.; Goupille, P.; Korotaeva, T.; Gottlieb, A.B.; et al. Secukinumab versus adalimumab for treatment of active psoriatic arthritis (EXCEED): A double-blind, parallel-group, randomised, active-controlled, phase 3b trial. Lancet 2020, 395, 1496-1505. [CrossRef]

28. Mease, P.J.; Smolen, J.S.; Behrens, F.; Nash, P.; Leage, S.L.; Li, L.; Tahir, H.; Gooderham, M.; Krishnan, E.; Liu-Seifert, H.; et al. A head-to-head comparison of the efficacy and safety of ixekizumab and adalimumab in biological-naïve patients with active psoriatic arthritis: 24-week results of a randomised, open-label, blinded-assessor trial. Ann. Rheum. Dis. 2019, 79, 123-131. [CrossRef]

29. Van Kuijk, A.W.R.; Gerlag, D.M.; Vos, K.; Wolbink, G.J.; De Groot, M.; De Rie, M.A.; Zwinderman, A.H.; Dijkmans, B.A.C.; Tak, P.P. A prospective, randomised, placebo-controlled study to identify biomarkers associated with active treatment in psoriatic arthritis: Effects of adalimumab treatment on synovial tissue. Ann. Rheum. Dis. 2008, 68, 1303-1309. [CrossRef]

30. De Groot, M.; Picavet, D.I.; Van Kuijk, A.W.; Tak, P.P.; Bos, J.D.; De Rie, M.A.; Teunissen, M.B. A Prospective, Randomized, Placebo-Controlled Study to Identify Biomarkers Associated with Active Treatment in Psoriatic Arthritis: Effects of Adalimumab Treatment on Lesional and Nonlesional Skin. Dermatology 2012, 225, 298-303. [CrossRef]

31. Chandran, V.; Schentag, C.T.; Gladman, D.D. Sensitivity of the classification of psoriatic arthritis criteria in early psoriatic arthritis. Arthritis Rheum. 2007, 57, 1560-1563. [CrossRef] [PubMed]

32. Taylor, W.; Gladman, D.; Helliwell, P.; Marchesoni, A.; Mease, P.; Mielants, H. CASPAR Study Group Classification criteria for psoriatic arthritis: Development of new criteria from a large international study. Arthritis Care Res. 2006, 54, 2665-2673. [CrossRef]

33. Smeets, T.J.M.; Kraan, M.C.; Galjaard, S.; Youssef, P.P.; Smith, M.D.; Tak, P.P. Analysis of the cell infiltrate and expression of matrix metalloproteinases and granzyme B in paired synovial biopsy specimens from the cartilage-pannus junction in patients with RA. Ann. Rheum. Dis. 2001, 60, 561-565. [CrossRef]

34. Conover, J.W.; Iman, R.L. Analysis of covariance using the rank transformation. Biometrics 1982, 38, 715-724. [CrossRef]

35. Johansen, C.; Usher, P.; Kjellerup, R.; Lundsgaard, D.; Iversen, L.; Kragballe, K. Characterization of the interleukin-17 isoforms and receptors in lesional psoriatic skin. Br. J. Dermatol. 2009, 160, 319-324. [CrossRef] [PubMed]

36. Harper, E.G.; Guo, C.; Rizzo, H.; Lillis, J.V.; Kurtz, S.E.; Skorcheva, I.; Purdy, D.; Fitch, E.; Iordanov, M.; Blauvelt, A. Th17 Cytokines Stimulate CCL20 Expression in Keratinocytes In Vitro and In Vivo: Implications for Psoriasis Pathogenesis. J. Investig. Dermatol. 2009, 9, 2175-2183. [CrossRef]

37. Li, J.; Chen, X.; Liu, Z.; Yue, Q.; Liu, H. Expression of Th17 cytokines in skin lesions of patients with psoriasis. Acta Acad. Med. Wuhan 2007, 27, 330-332. [CrossRef]

38. Kozlov, S.V. Inflammation and cancer. Methods and protocols. Volume 1: Experimental models and practical approaches. Preface. Methods Mol. Biol. 2009, 511, v-viii. [CrossRef] [PubMed] 
39. Johnston, A.; Guzman, A.M.; Swindell, W.R.; Wang, F.; Kang, S.; Gudjonsson, J.E. Early tissue responses in psoriasis to the anti-TNF- $\alpha$ biologic etanercept suggest reduced IL-17R expression and signalling. Br. J. Dermatol. 2014, 171, 97-107. [CrossRef] [PubMed]

40. Frleta, M.; Siebert, S.; McInnes, I.B.; Frleta-Gilchrist, M. The Interleukin-17 Pathway in Psoriasis and Psoriatic Arthritis: Disease Pathogenesis and Possibilities of Treatment. Curr. Rheumatol. Rep. 2014, 16, 414. [CrossRef] [PubMed]

41. Mease, P.P.; Gladman, D.D.; Ritchlin, C.; Ruderman, E.E.; Steinfeld, S.D.; Choy, E.H.S.; Sharp, J.J.; Ory, P.P.; Perdok, R.R.; Weinberg, M.M.; et al. Adalimumab for the treatment of patients with moderately to severely active psoriatic arthritis: Results of a double-blind, randomized, placebo-controlled trial. Arthritis Care Res. 2005, 52, 3279-3289. [CrossRef]

42. Milanez, F.M.; Saad, C.G.S.; Viana, V.T.; Moraes, J.C.B.; Périco, G.V.; Sampaio-Barros, P.D.; Goncalves, C.R.; Bonfá, E. IL-23/Th17 axis is not influenced by TNF-blocking agents in ankylosing spondylitis patients. Arthritis Res. Ther. 2016, 18, 52. [CrossRef] [PubMed]

43. Walters, H.M.; Pan, N.; Lehman, T.J.; Adams, A.; Kalliolias, G.D.; Zhu, Y.; Santiago, F.; Nguyen, J.; Sitaras, L.; Cunningham-Rundles, S.; et al. The impact of disease activity and tumour necrosis factor- $\alpha$ inhibitor therapy on cytokine levels in juvenile idiopathic arthritis. Clin. Exp. Immunol. 2016, 184, 308-317. [CrossRef] [PubMed]

44. Van Mens, L.J.J.; Van De Sande, M.G.H.; Menegatti, S.; Chen, J.; Blijdorp, I.C.J.; De Jong, H.M.; Fluri, I.A.; Latuhihin, T.E.; Van Kuijk, A.W.R.; Rogge, L.; et al. Brief Report: Interleukin-17 Blockade with Secukinumab in Peripheral Spondyloarthritis Impacts Synovial Immunopathology Without Compromising Systemic Immune Responses. Arthritis Rheumatol. 2018, 70, 1994-2002. [CrossRef] [PubMed]

45. Khatri, A.; Klünder, B.; Peloso, P.M.; Othman, A. Exposure-response analyses demonstrate no evidence of interleukin 17A contribution to efficacy of ABT-122 in rheumatoid or psoriatic arthritis. Rheumatology 2018, 58, 352-360. [CrossRef] [PubMed] 